\title{
The Use of Economics in International Trade and Investment Disputes: A Coherent Way Forward ${ }^{1}$
}

\author{
Marion Jansen, Joost Pauwelyn and Theresa Carpenter ${ }^{2}$
}

\section{Abstract}

In this paper we assess the quality and coherence of the use of economics in dispute settlement in two fields of international economic law: international trade and international investment law. We argue that four economic concepts are frequently used and/or of critical importance for both international trade and investment law. Those concepts are the concepts of "likeness"/"like circumstances", causality, "necessity" and damage calculation. We highlight differences in the way in which economics has been applied to assess these concepts and argue that coherence in the use of economics can be increased by reassessing the way in which economics is brought into submissions by parties and the processes that are relevant for adjudicators when interpreting economic evidence. We argue that a common set of guidelines for submitting quantitative evidence in WTO or investor-state dispute settlement proceedings can contribute greatly to setting quality standards and to creating trust as to the reliability and acceptability of economic evidence submitted to adjudicators. In an appendix to this paper we make suggestions as to what such guidelines could look like.

\footnotetext{
${ }^{1}$ This paper was partly authored with support from the project 'Dispute Settlement in Trade: Training in Law and Economics' ( www.dissettle.org ), a Marie Curie Initial Training Network funded under the EU Seventh Framework Programme (Grant Agreement No FP7-PEOPLE-2010-ITN_264633). The paper draws heavily on the contributions to the forthcoming volume Jansen, Pauwelyn and Carpenter (Eds.): "The Use of Economics in International Trade and Investment Disputes", Cambridge University press, and all the contributors to that volume are herewith thanked. The authors would also like to thank Manuel Sanchez Miranda for editorial assistance. All errors and omissions remain the authors' and views expressed are personal and do not reflect the views of the institutions they are affiliated to.

${ }^{2}$ Marion Jansen (jansen@intracen.org) is Chief Economist at the International Trade Centre, Geneva, Switzerland. Joost Pauwelyn (joost.pauwelyn@graduateinstitute.ch) is Professor of Law at the Graduate Institute in Geneva and Georgetown Law Center. Theresa Carpenter (theresa.carpenter@graduateinstitute.ch) is Executive Director of the Centre for Trade and Economic Integration (CTEI) at the Graduate Institute in Geneva.
} 


\section{Contents}

Introduction or why this topic is critical for public acceptance of future trade and investment treaties 3

Trade and investment: a divorced couple that is considering remarriage ................................... 4

Trade and investment disputes: what drives them apart............................................................. 5

Trade and investment disputes: what brings them together ...................................................... 5

Increased coherence: critical for the sustainability of disputes settlement in international

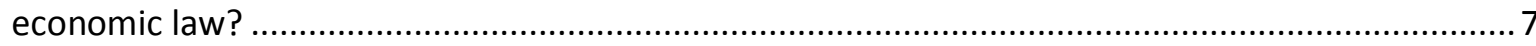

How much "economics" in international economic law? .............................................................. 7

Encouraging coherence across trade and investment disputes ..................................................

Bringing economics into submissions by parties: best practice .............................................. 10

Interpreting economic evidence submitted by parties............................................................... 11

Economics in trade and investment disputes: looking ahead ...................................................... 13

Appendix: Guidelines for submitting quantitative evidence in WTO or investor-state dispute

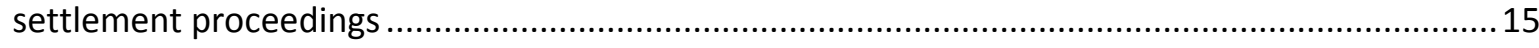

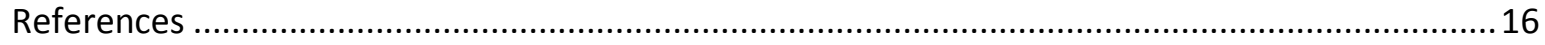




\section{Introduction or why this topic is critical for public acceptance of future trade and investment treaties}

Global markets have become increasingly integrated both in terms of the size of trade and investment flows and in terms of the number of players involved. They are governed by a set of national, regional and global legal frameworks for trade and for investment that interact at different levels. Increasingly the question arises how those frameworks fit together and how they can be made more coherent. Indeed, with the increased role of large multinationals - which dominate international trade, foreign direct investment and are large enough to exercise market power - the intertwined relationship between trade and investment law is becoming more and more obvious.

We focus in this paper on one particular aspect of this relationship: the quality and coherence of the use of economics in dispute settlement across these two fields of international economic law.

Admittedly, this may at first sound like a highly technical, potentially complex and rather boring topic. Yet, we will argue in this paper that this topic is of critical relevance for the sustainability of international economic treaties as we know them. This is the case, because the theme goes to the very heart of the 'raison d'être' of treaties of international economic law and of their acceptance by the general public.

When members to treaties of international economic law are in disagreement, this can give rise to disputes. Some of those disputes have ended up becoming top news items, notably when they led to signs of public discontent. The latter has happened several times in the recent past when disputes were dealing with important public policy issues, like in the case of the so-called beef-hormones or biotech products disputes (US-EC) at the WTO or the ISDS cases regarding regulation of cigarette marketing (Phillip Morris - Australia, also a WTO dispute) or the phasing out of nuclear energy (Vattenfall - Germany). In the case of negotiations of the Transatlantic Trade and Investment Partnership (TTIP), the potential of Investor State Dispute Settlement (ISDS) within this framework has led to protests and significant public debate.

In disputes as the ones mentioned in the previous paragraph, adjudicators' decisions were arguably perceived as unduly restricting national governments' ability to pursue valid public policy objectives. In other cases, the compensation governments were asked to pay to private investors in the context of ISDS has been perceived as unduly high. This happened even though the relevant legal instruments and dispute settlement procedures foresee that due attention is paid to those aspects and even though the relevant adjudicators did examine those aspects.

The attention those cases received suggests that future dispute decisions will increasingly be subject to scrutiny by experts and civil society alike. The quality of those decisions may therefore determine to which extent dispute settlement rulings are accepted and implemented and to which extent relevant international economic treaties continue to receive public support. In this paper we argue that the quality and coherence of the use of economics in dispute settlement will be an important factor in this context.

Trade, investment and competition law have in common that they regulate economic relations among private or public stakeholders. They are therefore typically considered to fall under the 
umbrella of "international economic law". Although the term "international economic law" makes the role of economics for these fields of law rather explicit, the use of economics in disputes has been very different across the three fields and has only found broad acceptance in one of them: competition law. In the area of investment and trade, the relevant dispute settlement bodies appear to have struggled with the questions whether, how much and how to use economic reasoning or evidence in the context of disputes settlement. This is even more surprising if one recalls that economists have sometimes contributed prominently to drafting the treaties that give basis for the disputes.

In this paper we argue that four economic concepts are frequently used and/or of critical importance for both trade disputes and ISDS. Those concepts are the concepts of "likeness"/"like circumstances", causality, "necessity" and damage calculation. Drawing on contributions to a forthcoming volume we are editing, we highlight differences in the way in which economics has been applied to assess such economic concepts across the two disciplines of economic law. While some of those differences may result from differences in legal concepts or institutional set-ups applied in trade disputes and ISDS, other differences appear to arise from an incoherent use of economics across the two fields.

Coherence in the use of economics can in our view be increased by reassessing the way in which:

Dconomics is or is not brought into submissions by parties to trade disputes or ISDS;

$>$ Submitted economic evidence is interpreted by adjudicators;

In this paper we provide practical guidance on how challenges in each of these three aspects can be addressed. We notably argue that a common set of guidelines for submitting quantitative evidence in WTO or investor-state disputes settlement proceedings can contribute greatly to setting quality standards and to creating trust as to the reliability and acceptability of economic evidence submitted to adjudicators, who are often not economic experts. In an appendix to this paper we make suggestions as to what such guidelines could look like, thereby providing a concrete contribution towards a more coherent use of economics in trade and investment disputes.

\section{Trade and investment: a divorced couple that is considering remarriage}

Though highly relevant for today's public debate, the question of how trade and investment can fit together within one single treaty is not new. The Havana Charter that was negotiated in the aftermath of the second World War, contained provisions on trade, investment and competition policy within one single legal document. This reflected a continuation of commercial practices whereby notably trade and investment matters were regulated within single legal texts. In the $19^{\text {th }}$ century, for instance, bilateral treaties around the setting up of foreign trading posts to sell goods addressed trade and investment in one document (Pauwelyn, 2014; Tietje et al., 2014).

Ultimately only chapter 4 of the Havana Charter has been adopted and this chapter only dealt with trade matters. With the adoption of what was to be called the General Agreement on Tariffs and Trade (GATT), a multilateral agreement was born that solely focused on trade matters. This marked the beginning of a period of several decades in which matters of trade, investment and competition policy were to be handled within separate legal frameworks and by different sets of legal institutions. 
This period is arguably coming to an end with the negotiation of so-called mega-regional agreements in the second decade of the 2000s. The newly-concluded Trans-Pacific Partnership (TPP) and the Comprehensive Economic and Trade Agreement (CETA) between Canada and the European Union (EU) both cover matters of trade, foreign direct investment and competition under the umbrella of a single legal text, as will the Transatlantic Trade and Investment Partnership (TTIP) being negotiated between the EU and the United States. Also China's Belt and Road Initiative covers both trade and investment aspects.

\section{Trade and investment disputes: what drives them apart}

Notwithstanding this "rapprochement" between trade and investment in recent international treaties, dispute settlement mechanisms in the investment and in the trade realm are characterized by a number of fundamental differences (see Gaukrodger, D. and K. Gordon, 2012).

One difference relates to the legal basis for dispute resolution. ISDS' legal basis is spread around dispute resolution provisions contained in around 3000 bilateral investment treaties, in a number of international conventions (e.g. the ICSID Convention, NAFTA and TPP) and in arbitration rules and contracts. The legal basis for trade disputes, instead, is anchored in Annex 2 of the WTO Agreement: the Understanding on Rules and Procedures Governing the Settlement of Disputes. A number of regional agreements also contain dispute provisions, but the WTO's DSS remains the most important reference point for disputes in the field of international trade.

ISDS draws on ad hoc party appointed arbitration panels (not subject, to date, to an appellate mechanism), while the WTO DSS foresees that the appointment of panellists is by agreement of both parties or by the WTO Director General (subject to appeal before the WTO Appellate Body whose seven members are appointed by consensus of all WTO members) (see Pauwelyn, 2015).

Another major difference is that ISDS allows private parties to bring claims against states, while in the case of the WTO only states can bring claims against other states. In addition, under ISDS claimants typically seek monetary compensation, whereas the final remedy in WTO disputes is a withdrawal of measures that are found to be WTO inconsistent. Retaliatory measures may be applied by the harmed parties, pending withdrawal but compensation for past harm - the standard remedy in ISDS cases - is not foreseen in the WTO/trade system.

\section{Trade and investment disputes: what brings them together}

Notwithstanding these differences, the two dispute settlement systems are also marked by numerous similarities. One of the similarities most relevant for this paper is that the economic concepts most frequently dealt with by adjudicators have a lot in common.

For instance, in both trade disputes and ISDS, the question arises how the line of economic activity that is said to have suffered from government intervention relates to other economic activities. In trade disputes, this question arises at the dispute stage in cases where it is necessary to assess whether imported products have been treated less favourably than domestically produced "like" 
products. Economic analysis has been used in a number of cases that involved assessing the "likeness" of products. ${ }^{3}$ Parallels have also been drawn in the literature between the concept of "likeness" in trade disputes and the concept of "relevant market" in merger cases (Melischek, 2013) or investors in "like circumstances" for purposes of national treatment in ISDS disputes (Pauwelyn and DiMascio, 2008).

A related question has also arisen in the context of ISDS damage calculation, where arbitrators have been led to apply "but for ..." assessments in order to evaluate what the value of the claimant's investment or company would have been, but for the allegedly wrongful government intervention. In such cases stock market indices composed of companies "within the same industry" have sometimes been used to assess trends and evolutions in the absence of government intervention (e.g. Abdalla and Rozenberg, forthcoming) . De facto, therefore, the composition of the market index has been assumed to give a reliable indication about a concept that is related to the concepts of "likeness" and "relevant markets".

A second concept that plays a role in both trade disputes and ISDS is that of "causation". In trade disputes the question of causation arises prominently in cases evoking the Agreement on Subsidies and Countervailing Measures (ASCM) when claimants argue that a defendant's policy has caused material injury or other adverse effects. The term causation here refers to the need to establish that any injury has its origin in the evoked government policy and not in any other policy, economic or other phenomenon that may have occurred at the same time. The same question arises in the context of ISDS damage calculations where it needs to be established whether any losses by the claimant during the identified period may be related to factors other than the allegedly wrongful action by the defendant state.

A third concept relevant for both trade and ISDS is the concept of "necessity". "Necessity" plays a role when the defendant government evokes the need to introduce a specific policy for legitimate policy reasons. In multilateral trade law the original GATT text -dating from 1947 - already foresaw in Article XX that governments may at times be induced to use policies "necessary" to pursue legitimate policy objectives - such as public health or safety - that may have the side effect of distorting trade flows. Governments' desire to pursue legitimate policy objectives has also been recognized in numerous other WTO and free trade treaties, although this is only a relatively recent phenomenon occurring in the latest generation of investment treaties (Tietje et al., 2014). The concept of "necessity" has therefore also been evoked by defendant states in ISDS including through reliance on the concept of "economic necessity" in the wake of a financial crisis under general international law rules on state responsibility.

Last but not least in this non-exhaustive list of similarities comes the fact that arbitrators in both trade and investment disputes have to assign a numerical value to the harm caused by the measure that is found to infringe the relevant rules (Bown and Pauwelyn, 2010). Until relatively recently when it came to calculating damages or permitted trade retaliation, WTO arbitrators as well as investorState tribunals, would resort to 'splitting the difference', that is adding up what the two opposing parties claimed and then awarding half of that amount, rather than using sound economic models and data (Pauwelyn, 2013). Increasingly though it is accepted that quantitative economic methods can play a valuable if not necessary tool in this phase of trade or investment disputes.

\footnotetext{
${ }^{3}$ Those cases are Japan - Alcoholic Beverages II, Korea - Alcoholic Beverages, Chile - Alcoholic Beverages, Philippines - Distilled Spirits and Thailand - Cigarettes. See also the discussion in lacovides and Jansen in this volume.
} 
Jansen, Pauwelyn and Carpenter

Increased coherence: critical for the sustainability of disputes settlement in international economic law?

The communalities described above refer to four questions that form crucial elements of trade and investment dispute settlement. Handling these questions in an appropriate and coherent way may prove to be crucial for the sustainability of dispute settlement in international economic law (IEL).

The concepts of "likeness" and "causation" are evoked in a large number of cases, which should represent a strong enough reason for requesting increased coherence and predictability regarding the approaches used to assess these questions. Such coherence is needed across different cases within the same field of IEL but also across different fields. This is in particular the case if trade and investment disciplines are dealt with within the same legal treaty and/or are applied to the same government policy. If questions of causality are addressed differently within trade disputes than within ISDS this may put the reliability of adjudication under such treaties into question.

Transparency and coherence regarding the assessment of "necessity" is at least equally important for the sustainability of dispute settlement in IEL. The term may systematically play a role in cases invoking public policy issues like health, the environment or economic/financial emergencies or crisis and thus cases that are likely to be under intense public scrutiny. As a consequence, adjudicators' approaches to dealing with "necessity" may influence greatly the extent to which governments and the public at large perceive IEL to restrain national governments' policy space. Responsible and coherent assessments of "necessity" may therefore be vital for continued public acceptance of trade and investment rulings involving public policy issues.

Last but not least, getting the calculations right when it comes to assessing damage or defining retaliation measures, may be crucial for continued acceptance of rulings by parties to the treaty. For the parties, especially claimants in ISDS, damage calculation is often the most important part of an award. For most law-trained adjudicators, in contrast, legal analysis is what they value and revel in, and damage calculation is often treated as a technical and at times annoying afterthought (Pauwelyn, 2013). Lack of attention to the remedies stage of cases and perceived inaccuracies or injustices at that stage, however, may bear the risk of decisions not being accepted and possibly not being implemented by parties to the relevant treaty.

The four areas that have been identified as critical here - likeness, causality, necessity and damage calculation - refer to notions that are fundamentally economic in nature. Not surprisingly, therefore, these four areas reflect areas where economic analysis has been relatively prominently used, with an emphasis on the term "relatively".

\section{How much "economics" in international economic law?}

Over the past four decades national courts in numerous countries have relied more and more on the use of economics in competition or antitrust law. Several institutions have developed guidelines for the use of economics in merger cases and it is common for economists and lawyers to work together on such cases. This evolution has not been welcomed by all and some experts argue in favour of a move back towards a higher emphasis on the basic legal (form rather than effects) aspects of antitrust law (Cavanagh, 2013). Numerous economists and legal experts in the field of trade and 
investment law nevertheless aspire to a situation where the use of economics in their field reaches the level of maturity that it has reached in antitrust law.

An increased use of economics in investment and trade law can have drawbacks. James Flett (forthcoming) emphasizes the significant resources that are required to handle economics appropriately in trade disputes and argues that more economics is therefore likely to lead to more inequality in the system. If the DSS is to remain an efficient tool for settling disputes and facilitating trade accessible to all members, pressures for economic analysis to spill-over from areas like competition law into the WTO - reflecting defendants' and advisors' vested interests - should therefore, in his view, be tempered. Thomas Graham (forthcoming) seems to suggest that an increased use of economics in trade and investment disputes may in any case not be 'commercially' viable, as law firms' international trade practices may not always find it straight forward to keep economists busy with revenue-producing work. Interestingly he appears to believe that it is easier to integrate accountants into law firms' work.

Others (including Breckenridge, Teh and Yanovich, and Unterhalter, forthcoming), instead, emphasise that an increased use of economics can increase the objectivity and predictability and therefore the quality of rulemaking. With the US - Upland Cotton dispute being an economics-heavy case in which a developing country - albeit an emerging one (Brazil) - prevailed over an industrialized country, there are also reasons to believe that the use of economics does at least not prevent developing countries from actively and successfully using the WTO dispute settlement system.

That said, the WTO dispute settlement system has not unequivocally embraced the use of economics, as notably described in Marios lacovides and Marion Jansen, Yanovich and Robert Teh and Pablo Bentes (forthcoming). As pointed out by Damien Neven and Petros Mavroidis (forthcoming), the conclusions of the annual American Law Institute Reports routinely feature expressions of dissatisfaction by authors with the quality of analysis and the lack of economic expertise included in panel and Appellate Body reports. Mavroidis and Neven also observe that panels and the Appellate Body have never so far commissioned independent economic expert reports.

Notwithstanding these observations, it is the case that a significant debate around the use of economics in WTO dispute settlement has taken place as notably reflected in the American Law Institute Reports and a number of other publications (e.g. Bown and Pauwelyn, 2010) including the WTO's World Trade Report (see notably the 2005 issue) and the WTO-supported refereed journal, the World Trade Review.

The debate on the relationship between law and economics is significantly less advanced in the field of investment law. It is widely accepted that a certain level of economics or "accounting" - in the terminology of Thomas Graham (forthcoming) - is necessary for damage calculation. Yet the methodological discussion on how to conduct such calculations is less advanced, notably when it comes to the question of how to assess causation. Also the question of how to assess whether different firms are active in similar product lines or industries (are investors in "like circumstances" for purposes of national treatment?) does not seem to have triggered the amount of soul searching that has taken place around the "likeness" concept in the trade community. Such differences across trade and investment dispute settlement are interesting and may be justified. They, however, suggest that there is significant scope for cross-fertilization between the law-and-economics-debates in the two fields. 
In order for this to happen and in order for the use of economics in trade and investment disputes to become more coherent and better integrated in the dispute settlement routine, a number of challenges have to be overcome. Some of those challenges go back to the fundamentals of why agreements exist and what they intend to achieve.

\section{Encouraging coherence across trade and investment disputes}

One of the differences between ISDS and WTO disputes appears to lie in the concept of justice that is applied in the two cases. According to Wolfgang Aschner (forthcoming) an Aristotelian notion of corrective justice tends to be applied for damage calculation under investment law. This notion considers that justice is done when the situation that existed prior to the wrongdoing is reestablished. The approach taken under ISDS is that corrective justice can be achieved if damages are equivalent to the liability caused by the wrong-doer and the losses suffered by the victim as a result of the breach.

Under WTO law instead, the purpose of the retaliation stage appears to be to induce compliance with WTO rules rather than to compensate for losses suffered by the victim (e.g. Malacrida, 2010). The purposes of the damage calculation under ISDS and the retaliation stage thus differ to a certain extent.

Another difference between the two fields appears to lie in the role expected benefits from the agreement play at the adjudication stage. Carla Chavich and Pablo López Zadicoff (forthcoming) illustrate that the question whether expected (ex-ante) returns from an investment undertaken under the umbrella of an investment treaty differ from the effective (ex-post) returns is central for investor-state disputes. A similar concept, i.t. the concept of nullification or impairment of the "benefits accruing directly or indirectly" to contracting parties under the WTO agreement, is also referred to in WTO legal texts (GATT Article XXIII). But this concept has not played a prominent role in dispute settlement (as there, any violation assumes the existence of nullification or impairment of benefits). One fundamental difference is that GATT Article XXIII refers to the trade (not overall welfare) benefits accruing to a country, whereas ISDS cares about benefits (in the sense of economic harm) to investors and thus private actors.

Other challenges that need to be overcome to better integrate economics into a dispute settlement routine are related to characteristics of the disciplines of law and economics rather than to the characteristics of trade and investment treaties. Anne van Aaken (forthcoming) points out that economics is a social science and relies - like other social sciences - on descriptions of implicit theories (e.g. "welfare maximization") of actors (e.g. "rational" agents, "benevolent dictators") and contexts (e.g. access to perfect information) that do not necessarily exist as such in reality (see also Bernstein et al., 2000). This makes the generation of prognosis complicated and often dependent on changing initial and boundary conditions. Knowledge generated by economics is therefore - in her view - often preliminary and tends to evolve. Law-makers and adjudicators therefore face the challenge of having to deal with evolving knowledge that can also lead to situations where competing theories exist.

The challenge discussed in Anne van Aaken's chapter may be compounded by the fact that the heavy use of mathematics by economists creates the impression that economics can generate very precise and solid prognoses. lacovides and Jansen (forthcoming) argue that quantitative analysis can indeed provide very precise guidance but that some of the precision lies in the fact that the analysis makes 
very explicit what is not known. While the identification of the unknowns can be considered desirable per se, it implies that economists have to rely on assumptions regarding the value of such unknowns in order to generate "precise" prognoses. Differing assumptions will lead to different prognoses and to the problem of competing evidence already mentioned above.

In the light of competing evidence, WTO panel and Appellate Body decisions appear to have struggled to take quantitative evidence submitted by parties on board. lacovides and Jansen argue that this is notably due to communication challenges between economists and lawyers and to the absence of a benchmark by which panellists can assess the quality of the quantitative evidence in a situation where both parties provide technical arguments in support or against the evidence that may sound equally convincing or non-convincing to a legal expert (and even sometimes to an economist).

Communication challenges and challenges on how to deal with evolving and possibly competing evidence will arise whenever teams of economists and lawyers work together to develop a common position or whenever adjudicators need to assess economic evidence. The following provides guidance on how to overcome such challenges.

\section{Bringing economics into submissions by parties: best practice}

A number of chapters in the forthcoming volume provide information and guidance on how economists and lawyers can or do work together when generating submissions of parties to dispute processes in the field of trade, investment or competition (notably Malashevich and Kobe, Breckenridge and Lau and Schropp). While Breckenridge's, and Lau and Schropp's contributions are rich in hands-on advice for practitioners, Maleshevich and Kobe provide - based on competition policy experience - insights into the universe of different ways in which economic evidence can be incorporated in cases of international economic law.

The contributions to that volume suggest that a close collaboration between economists and lawyers at an early stage e.g. for complainants when preparing a complaint or, for adjudicators, at the drafting stage, is key to generating clear, accessible and convincing arguments. While inputs from external economic advisers can be useful, those and any other economic evidence will need to be "translated" into legal language at the drafting stage (Lau and Schropp). A close collaboration between drafters from different backgrounds is necessary here to overcome communication challenges and generate a convincing case.

Lau and Schropp also argue in favour of keeping submissions simple and clear to facilitate to the extent possible the task of adjudicators to interpret presented economic evidence. In addition they suggest to direct different sections of submissions to different reader types, arguably as a way to facilitate communication. They notably suggest that:

(1) the highest level of abstraction should occur in the summary of the economic findings in the legal submission and the executive summary of any economic report accompanying it, as this part of a submission should be accessible to anybody;

(2) the main body of the report should be drafted such that it is understood by an interested nonspecialist willing to engage with the substance and to invest some time to get a closer understanding of the material; 
and finally, (3) the technical appendices of the economic report should be as thorough as typically required by state-of-the-art economic research papers, as these are ultimately addressed to economists supporting a WTO panel.

Similarly, Breckenridge suggests that simulation modelling has the potential to be a valuable addition to the economic toolkit available to trade litigators and adjudicators, provided certain guidelines are followed. He delineates a set of five principles for applying simulation models to trade disputes, suggesting that:

(1) parties to a case should be transparent regarding the assumptions they use when tailoring simulation models;

(2) models should replicate known characteristics of the market at issue, including market behaviour and the competitive interaction between parties;

(3) models should be tailored to the particular case at hand as this will better reflect the actual behaviour in the market;

(4) models should incorporate both quantitative and qualitative evidence, while the operation of the model at hand and its central insights should be explained in plain language without recourse to mathematical formulae; and

(5) it should be recalled that simulation modelling is but one species of quantitative modelling that could be used in disputes. The alternatives include econometric modelling and financial accounting models.

As with the suggestions from Lau and Schropp, the suggestions focus on a combination of simplicity and relevance.

\section{Interpreting economic evidence submitted by parties}

\section{Strengthening adjudicators' capacity}

A number of strong messages arise from the forthcoming volume regarding ways to address adjudicators' challenges when it comes to interpreting and assessing economic evidence.

Contributors to the volume (Mavroidis and Neven) argue in favour of including experts with economic expertise on panels or on the Appellate Body. This would make it easier to make reference to economic evidence presented by parties in adjudicators' decisions and to do so in a convincing and credible way. The importance of credibility in this context should not be underestimated. Indeed, we argued in the introduction that lack of credibility may expose dispute and arbitration decisions to criticism from parties or from civil society and possibly negatively affect the sustainability of the entire system.

\section{Strengthening the process}

When it comes to interpreting evolving or competing findings, adjudicators in the trade domain are currently in a very uncomfortable position that makes it difficult for them to assess conflicting information. The dispute settlement process as currently applied in the WTO makes it notably difficult for adjudicators to assess which position the "economic profession" would take in the relevant situation. This is the case for at least two reasons: 
- No rules exist as to the quality of the economic analysis in initial submissions, neither in terms of technical quality nor in terms of providing information on how economic statements in the submissions relate to other positions taken by the profession.

- Adjudicators have been rather conservative when it comes to being pro-active in their search for guidance on how to assess conflicting information. As a consequence, initial submissions by parties tend to create a status quo from which it is hard to evolve. WTO dispute settlement remains largely adversarial, driven by the parties, with panels hesitating to take a more proactive, inquisitorial stance.

An improved process would be a process by which adjudicators are more open to refer to economics in their decision while also being in a position to assess the quality of the submitted evidence and to assess how acceptable assumptions are that will inevitably have to be made in order to generate economic evidence.

Several contributors to the forthcoming volume (lacovides and Jansen; Teh and Yanovich) argue in favour of developing guidelines or benchmarks that help adjudicators - and in particular the noneconomists - to assess the quality of economic evidence provided. The Appendix to this paper contains a proposal of what such Guidelines could look like in terms of their technical content. It has been heavily inspired by existing guidelines for the submission of economic evidence to merger cases and by concrete proposals made in the chapter by Robert Teh and Alan Yanovich.

\section{Setting quality standards}

Guidelines for the submission of economic evidence should typically encourage parties to appropriately motivate and describe the use of data and economic methodologies in submissions. Ideally it should be understood that a failure to motivate and describe economic information will shed doubts on the quality of the presented economic evidence with likely negative repercussions on the way in which such evidence will be perceived by adjudicators in terms of quality.

\section{Creating trust as to reliability and acceptability of evidence}

Guidelines can also be used to encourage parties to provide information that would allow adjudicators to assess whether presented evidence would also find acceptance in the eyes of other, external economic experts. This can typically be achieved by requesting parties to position methodologies, data and findings within the existing literature as suggested by Teh and Yanovich and reflected in the Appendix to this paper. It should be understood that adjudicators will more easily accept findings that are in line with findings in other relevant literature and that result from the use of mature approaches, based on assumptions that are standard in the literature rather than representing minority positions.

Reliability can also be signalled by providing information about the robustness of findings that have been generated. This is typically achieved by showing that slight and realistic deviations from the selected approach generate similar findings (rather than wild deviations).

Last but not least, reliability can be signalled by creating a situation where adjudicators and possibly adverse parties can replicate economic findings presented by one of the parties. Guidelines may therefore request parties to submit all the data and methodological information necessary to replicate findings. Admittedly, confidentiality issues may play a role in cases where this may imply the sharing of sensitive information, but standard panel/ISDS working procedures include mechanisms for the submission of business confidential information $(\mathrm{BCl})$ that have withstood the test of time. 


\section{Linking economic evidence to the relevant legal questions}

For the purpose of the use of economics in dispute settlement it is not enough to show that presented evidence is of high quality and reliable, it also needs to be shown that the evidence is of relevance for the legal question at hand. Indeed, most of the contributors to our forthcoming volume agree that the legal analysis should continue to represent the core of any adjudication process. As a consequence, economic evidence should be required to support that legal analysis and parties should be required to make very clear why any selected economic method is relevant for the legal question under dispute. This requirement goes also to the heart of the communication challenges highlighted above. Economic evidence cannot be a stand-alone but needs to be embedded in the legal analysis in a digestible and convincing manner.

\section{Presenting economic evidence in an accessible way}

Adjudicators will find it easier to access and to accept submitted economic evidence if it is submitted in a standard way that allows them to know where to find information they may be looking for. Guidelines will therefore typically contain information on how to report economic findings in submissions.

\section{Allow adjudicators to be more proactive}

Different authors in our forthcoming volume have argued in favour of a more pro-active role for panels, the Appellate Body or investment tribunals when it comes to seeking guidance on how to interpret conflicting evidence in submissions by parties. David Unterhalter notably argues that WTO provisions do not impede adjudicators from being less conservative in their approach of handling economics. At least two approaches have been proposed in the chapters by Teh and Yanovich and by Mavroidis and Neven.

First, adjudicators may wish to conduct economic analysis themselves building upon the evidence provided by parties to a case. Amar Breckenridge illustrates in his chapter how some of the drawbacks of using simulation models in merger cases are addressed by the fact that competition authorities have the expertise and the freedom to recalibrate and re-run models submitted by parties. Mavroidis and Neven argue that nothing in the WTO agreements prevents adjudicators from doing so. Yet, adjudicators will have to remain mindful about the risk of pro-actively making the case in favour of or against one of the parties. In any event, when adding facts or economic studies to the record, also when these facts or studies are provided by WTO or ISDS Secretariat staff supporting panels or tribunals, adjudicators have to disclose them to the parties so that the parties can comment on or contest certain findings.

Second, the use of cross-examination among the parties should be considered in line with approaches applied in other domestic and international courts and in acknowledgement of the fact that economic experts will frequently give conflicting views about the factual and economic effects of disputed measures.

\section{Economics in trade and investment disputes: looking ahead}


International trade and investment law both have the objective to regulate economic relations among private or public stakeholders. Economic concepts therefore by nature have to play a role in settling any disputes that may arise in the relationships among such stakeholders. There may be disagreement about what this implies for the amount or nature of economic evidence that should ideally be submitted in the context of such disputes. But it will be hard to argue against the need for using economics coherently across the disciplines of trade and investment and also across different disputes within the same field of economic law.

We hope that the proposals in this paper regarding the strengthening of processes around the use of economics in disputes combined with the guidelines proposed in the appendix will make it easier to effectively use economics in trade as well as investment disputes. Guidelines like the ones in the appendix have been successfully applied by numerous national competition authorities. We are cognisant of the fact that it may be more difficult to establish such guidelines in the context of bilateral, regional or multilateral trade or investment agreements, but we nevertheless believe that it is worthwhile to make the attempt.

A more effective and possibly increased use of economics can in our view contribute to the sustainability of international dispute settlement systems and in particular the WTO and ISDS dispute settlement systems, as it may lead to an increased acceptance of dispute findings by affected parties and of panel/tribunal decisions by the general public. The latter is in our view particularly relevant in the context of cases that question the "necessity" of policy interventions that claim to pursue a legitimate policy objective.

Unfortunately it is precisely in this most sensitive area of dispute settlement that the economic profession is so far not very well equipped to provide guidance to adjudicators. This has been strikingly illustrated in the paper by Bown and Trachtman (2009) on the much-discussed Brazil-tyre case. The analysis by Bown and Trachtman shows - in our view - that economists can provide very precise and comprehensive guidance as to the nature and possibly magnitudes of trade-offs that adjudicators should take into account when assessing necessity. Yet economists are not always wellpositioned to provide precise values (i.e. precise quantitative information) of highly relevant variables like the health or social benefits of specific policy interventions.

We therefore end this paper with a call to legal experts to become more interested in the qualitative guidance economists can provide through examinations such as the one presented in Bown and Trachtman (2009). Those examinations may also be based on mathematical approaches, but do not generate 'numbers'. If they focus on identifying possible drivers of economic phenomena, identifying knowns and unknowns and on establishing orders of magnitude of variables of interest to panelists, such examinations can provide very valuable guidance for adjudicators. To this call to legal experts we wish to add a call to economists not to create unrealistic expectations as to what economics can do and to rather work towards a stronger evidence base that can guide adjudicators when they need to make decisions regarding important public policy issues like health and the environment. 


\section{Appendix: Guidelines for submitting quantitative evidence in WTO or investor-state dispute settlement proceedings}

These Guidelines suggest best practices when making submissions containing quantitative evidence to the WTO dispute settlement system either at the panel stage or the arbitration over retaliation (DSU Art. 22.6) stage. The Guidelines would not create any new rights or obligations, nor alter the rights and obligations arising from the existing WTO agreements. They merely stipulate which elements a sound economic submission based on quantitative evidence should contain in order to enable panels to use the evidence for making an objective assessment of the matter before it as foreseen in DSU Art. 11. These Guidelines can be adopted by panels or arbitrators as part of their Working Procedures pursuant to DSU Art. 12.1 after consulting with the parties. Given the generic nature of the Guidelines, they could also be incorporated in the dispute settlement procedures of investment agreements or working procedures of ICSID or other investor-state tribunals.

\section{General Guidelines}

1. Data requirements: Data submissions should be accompanied by a clear description of data sources as well as of hard copies of the data and databases employed in the analysis.

2. Model requirements: Parties submitting economic models are required to justify their methodological choices and the assumptions made in their models and to explain why these choices and assumptions fit the conditions that arise in the dispute. Such explanations will typically be accompanied be references to related academic literature.

\section{Guidelines for submission of econometric or simulation based evidence}

3. Methodology

a. The research question must be formulated unambiguously and properly motivated taking into account:

○ the legal provision that is being addressed in the analysis;

- the features of the products and/or markets under consideration; and

0 the relevant economic theory.

b. The choice of empirical methodology should be properly motivated and alternative methodologies should be discussed in the motivation.

c. In case of the submission of econometric evidence the hypothesis to be tested (or null hypothesis) must be clearly spelled out.

d. In case of the submission of evidence based on simulations, the baseline scenario has to be clearly stated.

4. The data

a. Data used in quantitative analysis should be thoroughly described. This includes reporting the sample time frame and the statistical population under consideration, the units of observation, a clear definition of each variable and a description of data cleaning procedures. This information should be accompanied by descriptive statistics (including means, standard errors, maximums, minimums, correlations, and histograms, residual plots, etc) of all relevant variables. 
b. Where the data is used in econometric exercises to support substantive claims, such as those about time trends and causal effects, parties should provide sample sizes that enable statistical inferences to be made.

c. If data have been collected through a survey, sampling methods have to be described and the utilized questionnaire has to be made available.

d. In simulation exercises, all parameter assumptions have to be clearly explained and justified making reference to all related literature and referring notably to:

- parameter assumptions made in related simulation exercises;

- econometric exercises that have generated estimates for the parameters under consideration.

\section{Robustness of results}

5. All empirical work should be accompanied by a thorough robustness analysis that checks whether empirical results are sensitive to changes in:

the data

o the choice of empirical model

○ the precise modelling assumptions

\section{Reporting and interpreting results}

6. The results of the empirical analyses should be reported in the standard format found in academic papers. For example, when reporting multiple regression results, both the estimated coefficients and the standard errors for all relevant variables should be reported.

7. Statistical significance of their results should be discussed and also their practical relevance. This requires interpreting the results in connection with the hypothesis that is being tested, so as to draw implications for the case under investigation. The results of the quantitative analyses should also be assessed with respect to the relevant economic theory.

8. The presentation of results should be accompanied by references to relevant quantitative literature. Results should be compared with findings in quantitative exercises using similar methods and conclusions should be drawn on the extent to which the submitted findings can be generalized.

9. Parties should explain the details of their models, and share any documentation needed to allow timely replication (e.g. the programming code used to run the analysis) and assessment of economic submissions.

\section{References}

** The forthcoming book volume (and individual chapters therein) referred to in this paper is: Jansen, Marion, Pauwelyn, Joost and Carpenter, Theresa., The Use of Economics in International Trade and Investment Disputes, Cambridge University Press, forthcoming 2016.

Bentes, Pablo M., "In Search of a 'Genuine and Substantial' Cause: The Analysis of Causation in Serious Prejudice Claims" in Jansen, M., Pauwelyn, J. and Carpenter, T., The Use of Economics in International Trade and Investment Disputes, Cambridge University Press, forthcoming 2016. 
Bown, Chad P. and Pauwelyn, Joost (2010) The Law, Economics and Politics of Retaliation in WTO Dispute Settlement. Cambridge, UK: Cambridge University Press, 2010.

Bown, Chad and Trachtman, Joel (World Trade Review 2009)): "Brazil-measures affecting imports of retreated tyres: a balancing act".

Breckenridge, Amar, "The games we play - Simulation models in merger analysis and their potential use in trade litigation" in Jansen, M., Pauwelyn, J. and Carpenter, T., The Use of Economics in International Trade and Investment Disputes, Cambridge University Press, forthcoming 2016.

Edward D. Cavanagh, Antitrust Law and Economic Theory: Finding a Balance, 45 Loy. U. Chi. L. J. 123 (2013).

Chavich, Carla and Lopez Zadicoff, Pablo, "Economics in Investor-State Arbitration Beyond Quantum" in Jansen, M., Pauwelyn, J. and Carpenter, T., The Use of Economics in International Trade and Investment Disputes, Cambridge University Press, forthcoming 2016.

Choi Won-Mog, 'Like Products' in International Trade Law. Oxford, UK: Oxford University Press, 2003.

Gaukrodger, D. and K. Gordon (2012), "Investor-State Dispute Settlement: A Scoping Paper for the Investment Policy Community", OECD Working Papers on International Investment, 2012/03, OECD Publishing. http://dx.doi.org/10.1787/5k46b1r85j6f-enGraham, Thomas, "Present at the Creation: Economists and Accountants in International Trade Law Practice" in Jansen, M., Pauwelyn, J. and Carpenter, T., The Use of Economics in International Trade and Investment Disputes, Cambridge University Press, forthcoming 2016.

lacovides, Marios and Marion Jansen, "Lost in Translation: Communication and Interpretation Challenges Related to Economic Evidence in Trade Disputes" in Jansen, M., Pauwelyn, J. and Carpenter, T., The Use of Economics in International Trade and Investment Disputes, Cambridge University Press, forthcoming 2016.

Laprévote, François-Charles, Sven Frisch, and Burcu Can. Competition Policy within the Context of Free Trade Agreements. E15Initiative. Geneva: International Centre for Trade and Sustainable Development (ICTSD) and World Economic Forum, 2015. www.e15initiative.org/

Lau, Christian and Schropp, Simon, "The Role of Economics in WTO Dispute Settlement and Choosing the Right Litigation Strategy - A Practitioner's View" in Jansen, M., Pauwelyn, J. and Carpenter, T., The Use of Economics in International Trade and Investment Disputes, Cambridge University Press, forthcoming 2016. 
Malacrida, Reto (2010) The case for multilateral regulation of the domestic decision-making process, in Bown, Chad P. and Joost Pauwelyn (Eds) The Law, Economics and Politics of Retaliation in WTO Dispute Settlement. Cambridge, UK: Cambridge University Press.Malashevich, Bruce and Kobe, Kathryn, "The Use of Economics in Competition Law: What Works and What Doesn't Across National Jurisdictions?" in Jansen, M., Pauwelyn, J. and Carpenter, T., The Use of Economics in International Trade and Investment Disputes, Cambridge University Press, forthcoming 2016.

Mavroidis, Petros and Neven, Damien, "Land Rich and Cash Poor? The Reluctance of the WTO Dispute Settlement System to Entertain Economics Expertise: an Institutional Analysis" in Jansen, M., Pauwelyn, J. and Carpenter, T., The Use of Economics in International Trade and Investment Disputes, Cambridge University Press, forthcoming 2016.

Melischek, Christian A. (2013) The Relevant Market in International Economic Law: A Comparative Antitrus and GATT Analysis. Cambridge University Press.

Pauwelyn, Joost and Nicolas Dimascio (2008) "Non-Discrimination in Trade and Investment Treaties : Worlds Apart or Two Sides of the Same Coin ?", 102 AMERICAN JOURNAL OF INTERNATIONAL LAW (2008) 48

Pauwelyn, Joost (2013) "The Use, Non-use and Abuse of Economics" in Huerta-Goldman, Romanetti and Stirnimann (Eds.) WTO Litigation, Investment Arbitration, and Commercial Arbitration, Kluwer Law International.

Pauwelyn, Joost (2014) "The Re-Convergence of International Trade and Investment Law: Causes, Questions, and Reform" in Proceedings of the Annual Meeting (American Society of International Law), Vol. 108 (April 2014), pp. 255-258

Pauwelyn, Joost (2015) "The Rule of Law Without the Rule of Lawyers? Why Investment Arbitrators Are from Mars, Trade Adjudicators Are from Venus" 109 American Journal of International Law (2015) 761-805

Teh, Robert and Yanovich, Alan, "Integrating economic analysis into WTO Dispute Settlement Practice: A View from the Trenches" in Jansen, M., Pauwelyn, J. and Carpenter, T., The Use of Economics in International Trade and Investment Disputes, Cambridge University Press, forthcoming 2016.

Tietje, Christian, Freya Baetens, Theodora N.Valkanou and Ecorys (2014), "The Impact of InvestorState-Dispute Settlement (ISDS) in the Transatlantic Trade and Investment Partnership", a study prepared for the Minister for Foreign Trade and Development Cooperation, Ministry of Foreign Affairs, The Netherlands.

Unterhalter, David, "On interpretation and economic analysis of law" in Jansen, M., Pauwelyn, J. and Carpenter, T., The Use of Economics in International Trade and Investment Disputes, Cambridge University Press, forthcoming 2016. 
Jansen, Pauwelyn and Carpenter

van Aaken, Anne, "What to Do if Economic Insights are Disputed: On the Challenge to Deal with Competing and Evolving Theories or Empirics in International Trade Disputes" in Jansen, M., Pauwelyn, J. and Carpenter, T., The Use of Economics in International Trade and Investment Disputes, Cambridge University Press, forthcoming 2016. 